\title{
Arendt and the politics of theory and practice: Beyond ivory towers and philosopher-kings
}

Theory \& Psychology

$0(0) 1-19$

(C) The Author(s) 2013

Reprints and permissions: sagepub.co.uk/journalsPermissions.nav DOI: $10.1177 / 09593543$ I3486955

tap.sagepub.com

@SAGE

\section{Denis Sindic}

Institute of Social Sciences of the University of Lisbon

\begin{abstract}
This paper draws on Hannah Arendt's political thought to question the relationship between theory and practice in psychology and the public role of psychologists. One of Arendt's main contributions to political theory was to underline the specificity of political action, and to stress that politics should not be ruled by pure theoretical reason or reduced to the technical management of social issues. Applied to psychology, a view of the relationship between theory and practice that ignores this specificity may well lead to efficacious applications, but it has a certain number of politically problematic consequences. These include the a priori disqualification of opinions, a loss of common sense, the a priori definition of the world as a set of variables, and the a priori definition of people as "material" to be shaped rather than as political actors. Such consequences are problematic insofar as they can lead to the exclusion of people from the public realm and undermine the very possibility of genuine political action. These points are illustrated and discussed through examples drawn from psychoanalysis and experimental social psychology.
\end{abstract}

\section{Keywords}

application, Arendt, political action, practice, technical

The purpose of this paper is to discuss some key political questions regarding the relationship between theory and practice in psychology. To do so, I will draw mainly on the political thought of Hannah Arendt. Accordingly, the first part will be devoted to outlining the main points of her thought on which the subsequent discussion will rely. Following Arendt, I will argue: (a) that the experience of being involved in theory-building may lead to a disregard of the "change of register" between theory and practice, which can

\section{Corresponding author:}

Denis Sindic, Instituto de Ciências Sociais da Universidade de Lisboa, Av. Prof. Aníbal Bettencourt, no.9, 1600-I89 Lisboa, Portugal.

Email: denissindic@yahoo.co.uk 
have problematic political consequences, and (b) that conceiving practice as the mere technical application of theory (the idea that people and society can and should be improved through psychological and/or social "engineering") can undermine the possibility of true political action. In the second part, I will explore the application of these points to psychology. To put some flesh on these abstract "bones," however, I will work on the basis of specific examples. Point (a) will be illustrated by looking at an example of the use of psychoanalytic theory in the public arena, whilst point (b) will be explored through the analysis of a classic discussion of the relationship between theory and practice in experimental social psychology.

\section{Ivory towers and philosopher-kings}

Whenever the relationship between theory and practice is discussed in psychological research, the most frequent complaint is to lament the fact that many theories lack concrete and practical applications. Indeed, a common perception is that researchers often tend to remain enclosed in their "ivory towers," either out of a lack of interest in leaving the safety of laboratories and the more prestigious world of fundamental research, or because they are incapable of doing so, their theories being too abstract or too simplistic to be successfully applied to the complexities of the real world.

Yet, the complaint could also be turned upon its head. Indeed, several important critiques of psychology are based on the argument that psychological techniques are nowadays part and parcel of a vast array of social practices (from businesses and the army to families) and are shaping our everyday lives in powerful but sometimes politically contestable ways (e.g., Foucault, 1976/1998; Pupavac, 2004; Reicher, 1996; Rose, 1999). More generally, as scientific theories leave the world of ivory towers to be applied in the "real" world, they inevitably become enmeshed with strategies of power (e.g., Latour, 1987; Mulkay, 1991; Stengers, 1993/2001). This means that the move from theory to practice does not merely raise epistemological and/or technical questions about whether one can do it, but also political questions as to whether one should: that is, whether such a move is politically legitimate and what are the political consequences of doing so.

Some of these political questions are the focus of this paper. The relevance of Hannah Arendt as a guide for discussing these issues springs from the fact that at the very heart of her work lies a constant attempt at rehabilitating the dignity of politics against the old prejudices towards this sphere of human activity - which for her crucially depends on defending the specificity of politics against its reduction to theoretical reason. She thereby proposes a reflection on the relationship between theoretical thought and political action, on which I will rely.

In scholarly terms, prejudices against politics can be traced back to the Greek philosophers, who pleaded for the valorization of a contemplative life dedicated to the pursuit of theoretical truth over one spent taking part in human political affairs - a hierarchization that has dominated the Western tradition of political thought ever since (Arendt, 1958, $1990,1994,2005)$. Together with this elevation of theoretical reason came a tendency to judge human affairs according to its standards, against which they were found to be lacking. By contrast with the orderly and meaningful world uncovered in the contemplative pursuit of truth, human affairs appeared messy and dominated by pettiness, and thus 
frequently became the object of the philosophers' lamentations. This is exemplified in their contempt towards the sophists, whose interest in politics went hand in hand with their interest in rhetoric and "mere" opinions.

Such derogation of human affairs also led some to the conclusion that, in order to overcome their "shortcomings," the only solution would be for those with the highest degree of theoretical wisdom to rule in the best interests of all. Otherwise put, the messiness of human affairs could be overcome by laying the standards of theoretical reason over them. This is best exemplified in Plato's idea of the philosopher-king.

As most modern readers will be aware, however, the sticky problem with this solution is that it basically constitutes a road towards tyranny. This, for Arendt, is no accident. Indeed she argues that the privilege accorded to theoretical reason, and its associated disdain for politics, have often gone hand in hand with a sympathy for tyrannical forms of regimes, pointing out "the frequently tyrannical tendencies so deplorably obvious among professional truthtellers" (Arendt, 2006, p. 235) from Plato to Heidegger (see also Arendt, 1978, 1990; Taminiaux, 1992/1997; Villa, 1996). Importantly, she also stresses that this tendency is not merely a harmless snobbery of philosophers, but also a key characteristic of many actual tyrannical regimes: the ruthlessly logical application of a grand theory of a utopian society which rides roughshod over all practical considerations, justifying all sacrifices in the name of their idealistic vision, as well as bypassing the messiness of a truly political process that could impede its application. This is why, for Arendt, it is absolutely essential to rehabilitate politics, given that its derogation is associated with real political dangers. She aims to remind us of the difference between the theoretical wisdom achieved through theoretical thinking and the practical wisdom necessary to partake in human affairs, and to warn us against the danger of allowing the former to become the sole guide for the latter.

The question that will be raised here, after a more detailed explanation of Arendt's work, is whether similar attitudes towards politics and political action can also be found within psychology - be it perhaps in less grand a way than with Plato. Certainly, few psychologists would explicitly defend ideas similar to the "philosopher-king" or confess sympathy for tyrannical regimes. Yet, this does not mean that the specificity of political action is always properly acknowledged. This raises the question of whether similar tendencies in conceiving the relationship between theory and practice can be found, with all the political consequences that it implies.

Before proceeding, however, two caveats are necessary. First, for the sake of simplicity, the following discussion conflates the concepts of theoretical reason, thinking, and (rational) truth. This is a fallacy in Arendt's own terms, as she took great pains to distinguish "genuine" thinking (an essential and highly valuable human faculty in its own right) from the building of systematic theoretical truths (Arendt, 1978). Her point, however, is precisely that these aspects have often been conflated in practice.

Second, by putting the emphasis on the (potentially "tyrannical") impact of theory on practice, my aim is certainly not to promote an intellectualist view of the penetration of psychological ideas within society. As Rose (1999) rightly points out, this process has been, first and foremost, a matter of practice driving theory (rather than vice versa), whereby it was the need to address practical problems that led to the development of new psychological techniques and theories (e.g., IQ testing in the army). Nevertheless, one 
may acknowledge this primacy of practice and still argue that, once they have emerged, theories and techniques may in turn affect the very way in which practical problems are conceptualized and formulated (see, e.g., Latour, 1987). In particular, my question concerns how the context in which these theories are produced may affect the way in which the relationship between theory and practice is generally conceived. Indeed, as I will argue, it is in that respect that Arendt's idea of an inherent tension between the life of the mind of theory-builders and the political life of citizens (Canovan, 1990) can make a specific contribution.

\section{Arendt on theory and practice}

\section{The specificity of action}

In order to grasp Arendt's notion of action, it is necessary to set it in the context of her distinction between labour, work/fabrication, and action, which constitute for her the three basic types of human activities (Arendt, 1958). These three spheres of activities correspond, respectively, to the human conditions of animal laborans, homo faber, and homo politicus. Labour (ponos) is the field of activities whose purpose is to maintain the cycle of biological life by seeing to its necessities (e.g., producing food). As such, they do not yield any enduring products as these are meant to be consumed as soon as they are produced. By contrast, work or fabrication (poiesis) refers to the activities of making the enduring artefacts and institutions that constitute the common world in which humans live. The products of fabrication are intended to be used rather than consumed. Fabrication is also the domain of utilitarian, instrumental reason, as it implies the calculation of the appropriate means necessary to achieve clearly defined ends. Finally, action, or doing (praxis), refers to the political business that takes place in this common world. It encompasses all the activities that relate essentially to the fact that we live together rather than as isolated individuals. That is, whereas labour and fabrication can both be affected by the presence of others, they can equally be performed in isolation. By contrast, plurality (i.e., the fact that individuals are not only distinct but also capable of actively distinguishing themselves from one another) is both the necessary condition and the reason for political action.

Action takes place within a web of agents, which both pre-exists and will outlive the individuals who constitute it at one point. The meaning of any act within that web is always ambiguous, as it can be interpreted in many different ways by those witnessing the act. The consequences of action are always irreversible (an act cannot be unmade as an artefact can), somewhat unpredictable and uncontrollable, as well as potentially boundless (as one action can trigger a chain of uncontrollable and unpredictable (re) actions throughout the web). Thus agents can never fully predict and control the scope, consequences, and meaning of their own actions, in the same way that fabricators can control the products of their fabrications.

Taken together, these characteristics or paradoxes of action (ambiguity, irreversibility, unpredictability, boundlessness - the list is not exhaustive) constitute what Arendt calls the frailty of human affairs. Political activity is about finding ways to deal with this frailty (e.g., counterbalancing unpredictability with pacts and treaties). However, it 
should also embrace these paradoxes as an essential and insuperable part of human affairs, for, as they constitute its necessary condition, trying to bypass or solve them once and for all would actually spell the death of politics - the arena within which humans express their (public) freedom (Arendt, 2006).

Action takes place within the public realm or the "common sense world of appearances" (Arendt, 1978): that is, what can be heard and seen by the web of actors, is the object of their deliberations, and can be affected by their actions (Benhabib, 1996). Within that public realm, Arendt maintains, the old philosophical distinction between truth, obtained through the exercise of reason, and mere opinion (doxa), reflecting only prejudices and illusions, does not hold. Indeed, she stresses that, in political terms, reason and opinion are far from being antithetical to each other and actually go hand in hand, for "when men exert their reason coolly and freely on a variety of distinct questions, they inevitably fall into different opinions on some of them" (Madison, as cited in Arendt, 1965, p. 227). Having a distinct opinion is a necessary condition to be an actor in the public realm, whilst a plurality of opinions is a necessary condition for a public realm to exist.

Action must also take place amongst "equals," in the sense that allies as well as adversaries must all be acknowledged as actors: that is, as able to have an opinion and capable of action. Those who are not acknowledged as such - e.g., women, slaves, and foreigners in ancient Greece, some of whom occupied important but essentially non-political positions - are excluded from the political realm, as they do not possess relevant opinions to be either supported or opposed. Action can only take place amongst other "free" actors (with or against them), for otherwise relations between them could only be of dominance and submission, meaning that the plurality of actors and their opinions would disappear to be replaced by the imposition of the opinion of one. Relationships of dominance/submission, as dominance either of the physical world or of other human beings, are the domain of labour and fabrication, not of action.

Arendt also argues that each sphere of human activity has its own specific criteria of excellence or wisdom, so that excellence in one area does not necessarily translate into excellence in another. The criterion of excellence in the activities of fabrication is technique (techne), the skillful application of a technical "know-how" necessary to find the appropriate means to achieve a determined end. The practical wisdom tied to action (phronesis) requires, amongst other things, the ability to exert one's judgement in always particular and ever-changing circumstances. Crucially, this ability cannot be reduced to the exercise of theoretical reason, as it is not equivalent to the logical application of the general to the particular, but is based on addressing the particular as particular (Arendt, 1978, 2003; see also Ricoeur, 1990/1992). Political judgement also requires the ability to represent to oneself and understand the greatest possible number and varieties of opinions about the world, not necessarily because they are all equally valid, but because they are key aspects that constitute the reality of the public world. As such, taking opinions into account is "the hallmark of all strictly political thinking," and "it is this capacity for an 'enlarged mentality" that enables men to judge" (Arendt, 2006, p. 237; this is in contrast with theoretical reason, which often requires the bracketing of opinions, as we will see below).

Both the activity of judgement and the practice of "enlarged mentality" are also deeply rooted in common sense, which Arendt (1972) defines as "our mental organ for perceiving, understanding, and dealing with reality and factuality" (p. 110). This sense of 
reality depends upon our interactions with others. That is, it flows from the fact that a variety of opinions can aim at the same reality despite having different points of views on that reality. In that sense, it is inevitably dependent upon the existence of a plurality of opinions and in their status as potentially valid viewpoints on the world.

\section{The privilege of theory over action}

As noted above, Arendt's argument is that the specificity of action has often been neglected or actively undermined within our tradition of thought. However, she also stresses that the reluctance to embrace the frailty of human affairs, and the tyrannical sympathies that can ensue from it, are not merely the contingent result of a specific tradition, or a question of individual psychology. Instead, she suggests that they may be linked to the very experience of theoretical thinking, and thereby constitute a sort of professional deformation (Arendt, 1971) or "occupational hazard" frequently experienced by "professional thinkers."

More specifically, she argues that, by nature, genuine thinking does necessitate a certain withdrawal from the world of human affairs, bracketing common sense and the plurality of opinions, at least for a while, for only in such conditions can thinkers explore new ways to see the world. But whilst this constitutes a normal part of the activity of thinking, the correlate is that thinkers also need to recover these aspects when coming back to the world of human affairs, as they are required to be an active participant within them. The trouble is that the experience of thinking can make it hard to do so, so that the temporary bracketing may easily turn into a more permanent loss. Indeed, when compared to the order and meaningfulness that can be achieved through the exercise of theoretical reason, it can become difficult to see the specific characteristics of action (ambiguity, unpredictability, etc.) as anything other than shortcomings to be overcome. Likewise, it can become difficult for thinkers to see opinions and common sense as anything other than fleeting shadows of the truths uncovered through their theoretical thinking.

As a result, thinkers may easily be tempted to replace the plurality of opinions by theoretical truths, using them as a higher source of authority that can arbitrate without appeal between opinions. By doing so, however, what they forget is that, in entering human affairs, "a shifting not merely from one kind of reasoning to another but from one way of human existence to another, has taken place" (Arendt, 2006, p. 233). Indeed, the consequence of this invasion of theoretical truths into politics is the undermining of the political realm itself, for "truth ... precludes debate, and debate constitutes the very essence of political life. The modes of thought and communication that deal with truth, if seen from the political perspective, are necessarily domineering" (Arendt, 2006, p. 237). Likewise, where thinkers do not reconnect with common sense, they are in danger of losing their capacity to judge and their sense of reality. The single voice of theory may do away with the need for representing to oneself the world from a multiplicity of points of views, but the price to pay is a loss of the sense of reality that was grounded in such plurality.

These points can be illustrated by an anecdote reported by Taminiaux (1992/1997) about Heidegger, whose involvement with Nazism has been well documented elsewhere (e.g., Farias, 1989; Rockmore, 1992). Taminiaux was attending one of Heidegger's seminars in which the latter was arguing against the dominance of instrumental reason in our 
contemporary world. In the midst of his argument, Heidegger declared quite seriously that tourism is something that should be forbidden. As Taminiaux confesses, under the spell of the implacable logic of the argument, he was ready to accept the idea that tourism was indeed an aspect of the instrumentalization of the world and thus should perhaps be forbidden. After the session, however, the common sense that had been set aside reasserted itself and made him ask some awkward questions. Can we really imagine implementing such a measure nowadays? Who is going to do it? And what about academics travelling around the world to give or attend seminars, as they were precisely doing at the time? However logical the conclusion might be, once we leave the world of thinking for the world of human affairs, it becomes simply absurd from the point of view of common sense, and, politically speaking, could only be realistically implemented through despotic measures.

\section{Replacing "doing" by "making": The alliance between thinking and fabrication}

The argument that the valorization of theory over action poses a political problem is still incomplete, however. After all, should thinkers withdraw into a life of contemplation, their political impact would be nil. The political tragedy only begins when thinkers decide to rejoin the political domain, without recovering what they had (temporarily) bracketed for the purposes of their specific activity. In doing so, they often look for ways to have a practical impact on the world while bypassing the frailty of human affairs - a "solution" that can be found by conceiving practice as an instance of fabrication.

Thus, an important part of Arendt's criticism is also aimed at the frequent substitution of action by the activity of fabrication. Such substitution is facilitated by the fact that, although fabrication is not similar to thinking, they have more affinity with each other than with action (Taminiaux, 1992/1997). Fabricators are the masters of their own fabrications, and proceed with a mental image of what is to be accomplished. Their task is to determine the best means through which this mental project can be actualized as faithfully as possible, predicting and controlling the effects of each step in the process. In that context, what fabrication offers to thinkers is the promise of being able to put their theoretical ideas into practice whilst keeping the same degree of predictability, control, and univocity found in the world of thinking.

But when political affairs are conceived along the lines of the model of fabrication, the result is that society is treated as an object that can be shaped by technical means, in the same way that, say, an architect constructs a building. And, as one commentator on Arendt points out, the political consequences of this can only be problematic:

The activity of work, of making, demands a unity of purpose in the adjustment of means to ends that can only be achieved either in solitude or by the rule of one man over others. Wherever politics has been visualized in the image of making something — as in many revolutionary theories - the implication of the need for central direction, unified sovereignty, naturally follows. So also does the need for violent transformation of the given "material," always part of the activity of fabrication ... order and predictability in gaining predetermined ends can be achieved only at the expenses of plurality and freedom. (Canovan, 1974, pp. 69-70) 
Thus, one of Arendt's key messages is that we should beware of politics being monopolized by "social engineers" (Ricoeur, 1983) and turned into a technical problem regarding the administration and handling of human beings.

To summarize, there are three points in Arendt's thought that are important for the following discussion. These are: (a) the necessity of acknowledging that there is a "change of register" between theory and practice, which implies that, within the public realm, opinions cannot be simply dismissed by reference to theoretical truth, (b) the necessity of avoiding replacing action with fabrication (i.e., seeing practice as a technical question of "social" or "human" engineering) if we are to preserve the existence of a genuinely political sphere, and (c) the fact that the tendency to ignore both these points can arise from the very experience of being involved with theory-building.

\section{Theory and practice in psychology}

\section{Theory vs. opinions and common sense}

In August 1997, in the midst of the ongoing turmoil following the arrest of the Belgian child rapist and murderer Marc Dutroux, the Belgian newspaper Le Soir published an interview with the psychiatrist and psychoanalyst Philippe van Meerbeek, a respected university professor and authority on youth psychopathology, in which he offered his diagnosis of Marc Dutroux based on psychoanalytic theories of perversion (in Lamensch, 1997a). ${ }^{1}$ He also explained how Dutroux's personality had been shaped by his dynamic with his parents, describing the father as "paranoiac and violent" and the mother as "fusional" and "incestuous." Two weeks later, a reply from Dutroux's mother was published in the same newspaper, in which she rejected the portrayal that was made of her, and questioned the psychiatrist's right to talk about people he had never met (Texto, 1997). The psychiatrist was prompt to reply that he had been expecting this kind of reaction all along, as it was typical of both Dutroux and his mother to try to pass themselves as victims, adding that "there is, after each accusation trying to attribute the blame to the other, a denial that paradoxically confirms the relevance of the diagnostic" (in Lamensh, 1997b).

This exchange illustrates how psychological knowledge, once it enters the public realm, can be used to disqualify "lay" opinions. My goal, however, is not to discuss whether or not the psychiatrist is right about the mother, but to examine the political consequences of making his statements within the public sphere. In that respect, the issue goes beyond the dismissal of a specific opinion (that of the mother about herself), for, if we accept the psychiatrist's claim to expertise, it is also the very status of this opinion as a claim to represent a potentially valid viewpoint on the world that is undermined. Indeed, whenever a question is defined as best answered by expert knowledge, we move from a scene where opinions compete against each other to a scene where, by contrast with expert knowledge, opinions become "lay" or "mere" opinions. That is, they are disqualified a priori, qua opinions, meaning that their claims to validity no longer need to be assessed through public debate. Thus, in this instance, we can see that the mother's reply is not treated by the psychiatrist as a competing viewpoint to his own, but reduced to another symptom confirming his initial diagnostic. Furthermore, as any disagreement 
from the mother would have entitled the psychiatrist to a similar response, it is also her very ability to hold any opinion whatsoever that is undermined. Like slaves and foreigners in ancient Greece, the diagnosed person, by virtue of the diagnosis itself, is being excluded a priori from the category of citizens entitled to a worthwhile opinion, and thus also from the public realm as a potentially relevant political actor.

That this kind of situation is not unusual is witnessed by the fact that psychoanalysts themselves often feel the need to warn against the use of psychoanalytic interpretations in the public sphere, insisting that the unconscious meaning of behaviour can only be properly explored through the thorough minutiae of a psychoanalytic therapy, in which the patient is actively and willingly engaged (e.g., Monfort \& Hourdé, 2005). As the psychoanalyst Sédat points out, in reaction to the proliferation of psychoanalytic interpretation in the media: "Every interpretation given to journalists or readers stays in the field of wild interpretation," adding that "one of the most subtle forms of violence, today, could be the violence of interpretation, putting one's word into someone else's mouth" (in Décugis, 2008, p. 1).

For some, such cautiousness may be driven by concerns about the epistemological validity of generalizing from therapy settings to the wider social context. In Sédat's case, however, his last sentence makes it clear that it is also, and perhaps primarily, a political issue. Within the context of therapy, psychoanalytic interpretations are a private matter between the psychoanalyst and the patient. In many circumstances, there may be good reasons for a psychoanalyst to interpret disagreement from a patient as a symptom of psychological resistance. However, once we leave this setting for the world of human affairs, such a gesture becomes loaded with consequences for the body politic as a whole. Indeed, as the above example demonstrates, it can result in putting psychoanalytic theories into the role of judging who can and who cannot take part in political affairs.

Should we then infer from van Meerbeek's intervention that he was simply unaware of the "official" rules of his own community? This is unlikely for a psychiatrist of his calibre. Following Arendt, one could suggest that a more interesting explanation goes beyond the specific individual involved and lies with the consequences of the experience of theory-building. Indeed, as with speculative thinkers, it is part of psychologists' job to take some distance with what opinions and common sense might suggest about the people or objects they are interested in. Concretely speaking, this is witnessed by the fact that they will typically collect the data used to support their theories in specifically designed settings that one could call (in a very large sense) "laboratories." Such settings purport to give them a better vantage point, precisely by putting them somewhat outside of the messy, ambiguous, and unpredictable world of human affairs. In the case of psychoanalysis, this place is the psychoanalytic cure.

There is, of course, nothing wrong in that process per se. However, it does raise the question of whether psychologists are able to reconnect with the specific "way of existence" inherent in the political sphere when deciding to take part again in human affairs. As suggested above, this may be rendered difficult owing to the persistence of "professional" reflexes and habits of thinking developed in the "laboratory." In that context, the psychiatrist's intervention could be explained by the fact that his focus on the theoretical question (i.e., "how can psychoanalytic theories make sense of this reality?") has overridden a consideration of the political implications of his statements. In other words, the 
bracketing of political considerations in the context of the cure has been transferred over into the public arena. Likewise, it is tempting to see the psychiatrists' dismissal of the mother's disagreement, and his disregard for the political consequences of such dismissal in the public realm, as the continuation of the professional reflex to question people's opinions about themselves and to interpret their disagreement as "resistance" in purely psychological terms.

What about the loss of common sense that can also result from ignoring this "change of register"? First, common sense might certainly question the ability to diagnose people without meeting them-indeed, as the mother's reply shows, one does not need to be an expert to make such a challenge. It may also very well question the appropriateness of describing her as "incestuous" on the basis that she allowed one of her sons (who was mentally unstable) to sleep in the same conjugal bed-that the term "incestuous" takes on a different, not necessarily literal meaning within psychoanalytic theory is precisely part of the problem. More importantly, regarding the question of the mother's blame, which the psychiatrist accuses her of avoiding by putting it onto others, common sense would certainly take note of the fact that, previous to Dutroux's arrest, she wrote to the authorities to warn them that he was sequestering young girls in his house. This is not mentioned in van Meerbeek's comment, but, should we pursue his reasoning (and it is only one small logical step), such a gesture could equally be interpreted as "posing oneself as a victim." With such an interpretation, common sense would indeed be turned upon its head, for the obvious public meaning of the mother's act would not only be dismissed but taken as proof of the opposite. It would also result in an intractable political implication, for should such logic be applied to all practical questions of blame attribution, all denials (and therefore all genuine attributions) of blame would become virtually impossible.

\section{Practice as technical application}

One could object to the above argument that most psychologists are well aware that the "real world" is always more complex than what happens in their "laboratories," and that this should be taken into account when applying theories. One important question, however, concerns the way in which they conceive of this complexity and how it should be taken into account. Does it arise from the nature of action itself: that is, from its specific traits (ambiguity, unpredictability, etc.) that are to be embraced as part of the frailty of human affairs? Or does it merely reflect limitations in our theoretical and technological tools? And is the implication that practice ultimately needs to be guided by a specific practical "wisdom," or that we need to improve both our theoretical knowledge and technical skills in order to overcome such difficulties?

In other words, the question that will be addressed here is whether practice is conceived of as action or fabrication within psychology. As before, the point of discussion is not whether treating practice as a technical issue is epistemologically justified, but, rather, whether it is politically desirable - in particular whether it is desirable to see practice as being only about technical applications. This will be explored by looking in detail at a chapter by John Turner (1981) which defends the generalizability and practical usefulness of experimentally based research and theory in social psychology. 
We can start by noting that, in his chapter, Turner explicitly defends the view that applied social psychology should be seen as "something like a science of social engineering" (p. 30), a term which, as we have seen, is strongly indicative of a view of practice as fabrication. Nevertheless, to go beyond the simple use of this term, let us look at the obstacles he invokes to explain the difficulties in translating theory into practice, for whether these call for improvements in theoretical, technical, or practical "wisdom" can tell us more about his conception of practice. Thus, for Turner, "the real obstacles to generalizing to applied contexts" are (a) "limitations in basic theory" and (b) "factual ignorance of the exact conditions which obtain in complex, real situations including our lack of suitable measurement techniques" (p. 29). ${ }^{2}$

Turner's first point is straightforward, as it calls for improvements in theoretical knowledge, particularly through fundamental, experimentally based research. His second point, however, reflects the awareness that the conditions in "real situations" are always more complex than in the laboratory and that this needs to be taken into account. Nevertheless, his overall argument suggests that dealing with such complexities is mainly a matter of overcoming theoretical and technical difficulties by developing more contextualized theories that incorporate them as additional factors as well as more "suitable measurement techniques."

In that perspective, the complexities of the "real world," like those of the laboratory, are conceived of as complicating variables which need to be factored into the "equation" of applying theories, like an engineer taking into account friction when applying the laws of motion. That is, they are aspects of the world potentially open to measurement once the proper technical tools can be developed. The task of applying psychological theories would then consist of identifying and finding ways to measure the variables that the laboratory has neglected. The only difficulty is that the "real world" contains many more of them and that they can be harder to measure. As such, our theoretical knowledge and technical mastery of these "real world" variables may perhaps never be perfect. Yet it is the ideal towards which one strives and which, in doing so, leads to real improvements.

The consequence is that the world is defined a priori as a set of variables waiting to be discovered and controlled instead of as a realm within which actors have to form opinions, judge, and act despite its essential uncertainties, and without the hope of ever being able to fully control the meaning and consequences of their actions. Practice is conceived of as the fabrication of a complex artefact for which technical—but no specifically political - talent is needed. The application of theories requires a technical know-how or "craftsmanship," such as an ability to draw the logical implications of theories in particular circumstances, identifying the relevant factors, and assessing their practical importance. As Turner (1981) puts it, "Sound application also depends upon expertise in applying pure theory to concrete settings and generating its specific technological implication" (p. 7).

Concomitantly, there is no suggestion that the difficulty of applying theories to practice may spring from the specific traits of action and thereby call for specifically political "solutions." Instead, these traits are recast as mere technical obstacles (albeit inevitable) to the smooth application of theories. This, one may argue, could be seen as the result of a habit of thinking and doing (or rather making) developed within the laboratory. Indeed, it is a normal part of laboratory work to define unwanted complications as technical 
obstacles ("noise," confounds, etc.) which should be controlled or removed (even if these need to be "recovered" later). The continuation of this habit outside of the laboratory is to see the complications of the public realm in the same terms and to think that they can be dealt with in a similar fashion.

In that respect, Turner's treatment of the issue of reactivity (to which a significant part of his chapter is dedicated) is symptomatic. In principle, reactivity could be seen as a sign of the essential ambiguity of action, as well as the unpredictability and uncontrollability of its consequences (i.e., people can interpret and react to an intervention in different and unexpected ways). However, far from being conceived of as such, reactivity is treated by Turner as just another type of technical obstacle that does not require any special treatment compared to the other "complexities" of the real world, and can be likewise bypassed or controlled to guarantee the applicability of theories. Thus, he argues that, within the laboratory, "competent researchers seek to eliminate [reactive effects] in the same way that they seek to eliminate any other plausible, alternative explanation of the data" (Turner, 1981, p. 13), and that, outside the laboratory, "reactivity would only be problematic if it were unlawful" (p. 28).

The point here is not that such a view is necessarily incorrect. On the contrary, the problem arises from the fact that it may well work. That is, it is the political consequences of extending that view outside of the laboratory, particularly where it is successful, that are in question. Indeed, as Spears and Smith (2001) argue, the laboratory is far from a democratic place, for it relies on the unilateral use of power by the experimenter over the participants (or, as they were once called, perhaps more aptly, the "subjects"). To control the effects of reactivity, for instance, one must at least (a) perform an "engineering of consensus" or eliminate "disputed meanings" (Spears \& Smith, 2001) - that is, make sure that one's intervention is read consensually and in the intended way by others (i.e., suppress the ambiguity of action) — and (b) ensure that the consequences of one's intervention can be fully controlled - that is, make sure that it will not lead to reactivity, or predict the direction of such reactivity so that it can be accounted for (i.e., go against the unpredictability and uncontrollability of the consequences of action). In short, as any competent experimentalist in social psychology well knows, good experimentation requires fabricating the context as well as manipulating people, and often in deceiving ways. This can only be realistically achieved through an undemocratic "political despotism." It also relies on defining people a priori as materials that can be manipulated in the same ways that artefacts can, and as subjects determined by predictable laws of behavior rather than as agents capable of unpredictable political action.

Spears and Smith (2001) further argue that this "undemocratic" aspect of experiments does not make them invalid and reject the view that "the experimental tradition of the natural sciences is fundamentally misguided as a model for the social world characterized by open systems and intentional agents" (p. 324). Instead, they propose that experiments should be conceived as "paradigms of power" and argue that, as long as we acknowledge the power dynamics, they can tell us about the workings of power in the larger social world. Arendt's argument implies that Spears and Smith may be quite correct in their position. If our society is characterized by undemocratic workings of power, then to use the undemocratic means of experimental methodology in order to understand 
them is perfectly appropriate from an epistemological point of view. However, it is one thing to try to understand these mechanisms, but it is another to try to reproduce them outside the laboratory so that the laws of human behaviours can be shown to be valid, by becoming so - that is, by making the social world become less of a place "characterized by open systems and intentional agents." By defining a priori political questions as amenable to technical solutions, and people as artefacts that can be manipulated, not only do we neglect the specificity of action, but we also run the risk that this may act as a selffulfilling prophecy.

\section{Practical implications}

Although this is not the main purpose of this paper, a few points in regard to the practical implications of the above arguments should be mentioned.

In regard to the relationship between theoretical knowledge and opinions, the implication is that when psychologists wish to take part in human affairs, they should be able to recognize the change of register and take into account the inescapable political nature of public discourse (e.g., Fox \& Prilleltensky, 1996). In particular, they should always consider the political consequences of their particular statements. The idea that public interventions of psychologists can and should be justified solely on the basis of the strength of the evidence supporting their theoretical knowledge (e.g., O’Donohue \& Dyslin, 1996) will simply not do. This is not to discard the value and usefulness of evidencebased knowledge (which may constitute one ingredient to be taken into consideration), but to underline that it cannot be used as a tool to "silence" the plurality of opinions on political questions and/or to replace the need for political debate. That is, the general message is not that psychological theories cannot be applied to practice, but that they should not rule it by being turned into the ultimate "standards" of human affairs, thereby removing or superseding the need to use one's political judgement in situ and to make committed political choices and decisions.

Importantly, it should be stressed that acknowledging opinions as potentially valid viewpoints on human affairs is not equivalent to taking the relativist's standpoint that they are, in actual fact, all equally valid. Certainly, opinions can be of different qualities, and whilst it is ultimately the role of public debate (not solely of experts) to decide on their validity, this means that we can make room for the possibility that psychological knowledge may help in the formation of better opinions. Nevertheless, the extent to which it can do so will depend not merely on the strength of the research evidence that supports it, but more crucially upon whether it can help us to understand the world from the point of view of others (i.e., helping us practise the "enlarged mentality"). In that respect, theories can prove as much of an impediment as a help, for they can also be used as a substitute for the need to take into account people's opinions about themselves and the world (by, for instance, defining them a priori as epiphenomena).

In regard to the treatment of practice as a technical issue, the point here is not that psychologists should automatically reject a technical approach and follow the model of action in all of their practical contributions. Instead, it is that we need to consider the political consequences of treating issues as belonging to one sphere or the other. In Arendt's thought, fabrication is a human activity with its own dignity and purpose. 
Far from necessarily undermining the possibility of action, it is in fact responsible for building the common, artificial world without which action would be impossible. The problem lies not in fabrication per se, but when it is used to replace action and eliminate rather than support the creation of public spaces where action becomes possible.

The political implication of defining an issue as a technical one is to withdraw it from the public realm as a legitimate object of opinion and of political decisions. Certainly, there are potential applications of psychology (e.g., designing road signs based on attention theory) that can be treated as technical issues without raising serious concerns as to the political consequences of doing so, in which case it may well be appropriate for psychologists to act as technicians and stay outside of the political debates. ${ }^{3}$ However, we can seriously doubt that this applies to many of the most important issues addressed by psychology. A great deal of social psychological research, for instance, deals with issues that have to do with the question of "What is a harmonious society?" This is obviously a question on which people usually both have and want to be able to have opinions. Undermining a priori the relevance of such opinions, as well as people's ability to hold them, would be equivalent to telling people that they cannot and should not play an active role in the way this question is (practically) addressed.

This is not to say that technical applications may not be considered on (limited) aspects of these issues. Rather, the question to ask in any particular case is whether psychologists' interventions support and enhance the possibility of action and of public debate, or whether they undermine it. When, for instance, psychologists suggest that teaching bilingualism at school does not necessarily create "language confusion" amongst children, but may on the contrary make them more "cognitively flexible" (e.g., Garcia, 1990; Hakuta, 1986), this performs a useful service if it is used to prevent the closure of political debates on this issue on technical grounds (i.e., we should not teach children two languages because it makes them less competent). It would, however, fall into the same pitfall should it be used to close the debate the other way round (i.e., we should teach children two languages because it makes them more competent). In both cases, providing this kind of definite answer relies on replacing the political question (i.e., Do we want a country where different languages are supported, with all the consequences for multiculturalism this implies?) by a technical one (i.e., How can we increase children's cognitive abilities?). That is, the issue is redefined as one for which the goal is settled (and who would indeed disagree with such a goal?), so that the only question left concerns the means to achieve it.

Obviously, these points have direct implications for the quality of democracy. As Stengers and Ralet (1997) point out, the democratic quality of our politics is a direct function of

the manner in which the political process addresses citizens, that is, anticipates-suggests what they are and what they are capable of, that will determine whether the democratic ethic is denied or affirmed. ... [A]ny method of management that implies the supposition-anticipationsuggestion of stupidity or infantilism of the individuals that constitute this society should be excluded; for, if they are defined as stupid or infantile, democracy itself can only be defined as manipulation, a modern, new way of leading the flock. (p. 223; see also Nowotny, 2003) 
The point here is similar vis-à-vis action. To paraphrase the above, social interventions should ideally suppose-anticipate-suggest that people are capable of action instead of trying to neutralize it as a troublesome capacity. They should also appeal to and make possible the exercise of practical wisdom, instead of replacing it by technical competence.

What this would mean more concretely, in practice, remains to be explored, and it is precisely not a question to be "solved" by scientists or scholars as if it were another technical issue. As Arendt (1958) puts it, the answers to these types of questions

are given every day, and they are a matter of practical politics, subject to the agreement of many; they can never lie in theoretical considerations or the opinion of one person, as though we dealt here with problems for which only one solution is possible. (p. 5)

Yet, what is certain is that practical psychology cannot support the possibility of action where the specific traits of actions as well as opinions and common sense are defined a priori as obstacles or variables to be controlled. By mentioning above the debate on bilingualism, however, my goal was also to illustrate - short of a more detailed answer - that there is nothing inevitable in that process and that psychologists and their theories can potentially play a positive as well as a negative political role in the public realm.

\section{Conclusion}

To conclude, a few words may be in order about why Arendt was chosen as a guide to the current reflections. After all, there are other important contributions to the issue of theory and practice (e.g., Bourdieu, 1980/1990), including some by psychologists directly addressing its political dimension (e.g., Fox \& Prilleltensky, 1996). A systematic comparison with those was beyond the scope of this paper, but some discussion as to how Arendt's thought can make an original contribution to the issue is warranted.

I contend that it is worth bringing her into the debate for at least two reasons. First, beyond merely exploring the differences between theory and practice, Arendt's thought can be useful to reflect upon the relationship between the particular experience of theorybuilding and the political ethos of theory-builders. As such, her approach can contribute to a better understanding of scientific activity and its political consequence, whereby, for instance, the stereotypical unworldliness often attributed to theoreticians, as well as their tendency to see the entire world in terms of variables, can acquire a meaning beyond their status as quirky and harmless "character traits."

Second, the originality of Arendt's argument is that she does not merely oppose theoretical to practical reason, to then simply denunciate the limits of one from the point of view of the other. Rather, her distinction between the different types of human activity (even if those should be considered as "ideal types," see Canovan, 1974) allows us to go beyond such a dichotomy, and thereby to think beyond the alternative of scientists as locked into their "ivory towers" vs. assuming the role of philosopher-kings.

Thus, on the one hand, Arendt's attacks on theoretical reason are not made from the vantage point of a practical reason defined in purely instrumental terms and concerned only with "what works," whereby the main deficiency of theory would be its ineffectiveness. 
On the contrary, by putting the political questions on the centre stage, the main cause for concern becomes precisely that in some cases the application of theory can work only too well. What need to be reflected upon are the political consequences of such applications, particularly in terms of the potential reduction of one sphere of human activity to another.

On the other hand, whilst Arendt's argument about fabrication can be seen as a critique of the limits of instrumental reason, of which there are more famous ones (e.g., Heidegger's), such critique is not done in favour of a withdrawal into contemplation (i.e., confronting one's mortality in Heidegger's thought) or to boast the virtues of theoretical knowledge for its own sake. Rather, it is done in the name of a freedom conceived as a "tangible worldly reality" which is to be found in the public sphere of politics and action, through "our intercourse with others, not in the intercourse with ourselves" (Arendt, 2006, p. 147). Such a perspective also radically departs from individualistic political and philosophical perspectives that see freedom as located primarily in the private sphere, the role of politics being limited to protecting it (i.e., freedom from politics vs. freedom through politics; Arendt, 2006). As such, it represents a vision that many psychologists (or at least those of the more social variety) may find appealing.

My purpose here, however, was not to offer definite solutions to these questions, but simply to show the importance of reflecting upon them. Providing more solid answers would of course require (for one thing) a more thorough and extended analysis of the field. More modestly, my goal was simply to show that these are relevant questions through the exploration of a couple of examples, letting the reader be the judge of how typical these examples are of the field in general. Also, the main point was to illustrate the existence of a tension between the activity of research/theory-building and taking part in human affairs, and to argue that psychologists need to be aware of it. This obviously does not imply that they are inherently incapable of resolving such tension in more satisfying ways than by mechanically imposing the logic of theory upon practice; nor does it mean that there are no sites or mechanisms by which "ordinary" citizens can resist the "silencing" of theory (another crucial question to explore). Finally, whilst I have focused on examples drawn from psychology, the same questions could obviously be asked from social sciences in general.

Nevertheless, as a final word, I also wish to stress the fact that this questioning should not necessarily lead us to be paralysed in our practices. Dismantling the dream of a mechanical application of our theories to the "real" world in favour of a respect for the frailty of human practices may act as a warning against our "expert power," which, if it is heard, could lead us to be even more shy about venturing outside our "ivory towers." Yet, the message could also be that, in order to do so, we do not need to wait until the day our theories are powerful enough so that we feel that this dream is closer to realization. Accepting the risks inherent in action, rather than trying to overcome them, and the realization that one cannot avoid "getting one's hands dirty" in politics when taking part in public issues, may well lead to a stronger and more fruitful relationship between theory and practice.

\section{Acknowledgements}

The author would like to thank Alan Collins, Ana P. Nunes, Orla Muldoon, Clifford Stevenson, Rob Lowe, Niamh McNamara, Emanuele Castano, Rui Costa-Lopes, Cicero Pereira, and Marcus 
Lima for their most helpful input on the first drafts of this manuscript. Special thanks in particular go to Alan Collins, who, in his detailed commentary, went significantly beyond the call of duty.

\section{Funding}

This research received no specific grant from any funding agency in the public, commercial, or not-for-profit sectors.

\section{Notes}

1. Psychoanalysis was chosen as an example because it is arguably the most successful of psychological theories in terms of its penetration of the public realm. As for this particular incident, it was chosen because it had the advantage of presenting a full round of exchange between expert and "lay" opinion.

2. Turner adds a third point, which is the "lack of practical control over relevant conditions," but whether this should be interpreted as a lack of technical or political control is left unclear. What is certain, however, is that this does not lead him to discuss how such "lack of control" might be an inherent characteristic of acting within the public realm. Rather, his argument implies that political questions are a separate matter that does not essentially affect the potential applicability of psychological theories.

3. This is not to say that such issues could not be seen as political, only that few, if any, would normally have an interest in doing so. In other words, the separation between political and technical issues can be more or less stable, though that stability can always be challenged. That is, the question of whether an issue is a technical or political problem can itself become a political question. Arendt herself can and has been criticised on this point (e.g., Benhabib, 1996).

\section{References}

Arendt, H. (1958). The human condition. Chicago, IL: University of Chicago Press

Arendt, H. (1965). On revolution. New York, NY: Viking.

Arendt, H. (1971). Martin Heidegger at 80. The New York Review of Books, 17(6), 50-54.

Arendt, H. (1972). Crises of the republic. New York, NY: Harvest.

Arendt, H. (1978). The life of the mind. New York, NY: Harcourt.

Arendt, H. (1990). Philosophy and politics. Social Research, 57, 73-104.

Arendt, H. (1994). Essays in understanding: 1930-1954 (J. Kohn, Ed.). New York, NY: Harcourt Brace Jovanovich.

Arendt, H. (2003). Responsibility and judgment (J. Kohn, Ed.). New York, NY: Schocken.

Arendt, H. (2005). The promise of politics (J. Kohn Ed.). New York, NY: Schocken.

Arendt, H. (2006). Between past and future: Eight exercises in political thought (J. Kohn, Ed.). London, UK: Penguin.

Benhabib, S. (1996). The reluctant modernism of Hannah Arendt. Thousand Oaks, CA: Sage.

Bourdieu, P. (1990). The logic of practice (R. Nice, Trans.). Stanford, CA: Stanford University Press. (Original work published 1980)

Canovan, M. (1974). The political thought of Hannah Arendt. New York, NY: Harcourt Brace Jovanovich.

Canovan, M. (1990). Socrates or Heidegger? Hannah Arendt's reflections on philosophy and politics. Social Research, 57, 135-165.

Décugis, J.-M. (2008, May 29). Jacques Sédat: : “Toute interprétation livrée aux journalistes et aux lecteurs reste dans le champ de l'interprétation sauvage.” [Jacques Sédat: “Every interpretation 
given to journalists or readers stays in the field of wild interpretation"]. Le Point. Retrieved from http://www.lepoint.fr/actualites-politique/2008-05-29/sarkozy-et-les-psys-jacquessedat-toute-interpretation-livree-aux-journalistes-et-aux/917/0/248930

Farias, V. (1989). Heidegger and Nazism. Philadelphia, PA: Temple University Press.

Foucault, M. (1998). The history of sexuality: Vol 1. The will to knowledge (R. Hurley, Trans.). London, UK: Penguin. (Original work published 1976)

Fox, D., \& Prilleltensky, I. (1996). The inescapable nature of politics in psychology: A response to O'Donohue and Dyslin. New Ideas in Psychology, 14, 21-26.

Garcia, E. (1990). Bilingualism and the academic performance of Mexican-American children: The evolving debate. ERIC Digest. ED321963. ERIC Clearinghouse.

Hakuta, K. (1986). Mirror of language: The debate on bilingualism. New York, NY: Basic Books. Lamensch, M. (1997a, August 12). Sur les enseignements de l'affaire dutroux pour un psychiatre spécialisé dans le traitement des jeunes [The lessons of the Dutroux affair for a psychiatrist specialized in youth treatment]. Le Soir, 2. Retrieved from http://archives.lesoir.be/sur-lesenseignements-de-1-affaire-dutroux-pour-un-psyc_t-19970812-Z0E2NY.html

Lamensch, M. (1997b, August 26). Le Pr van Meerbeeck réagit à la "lettre ouverte" de Jeanine Lauwens et maintient son diagnostic: "Marc Dutroux se pose en victime, comme sa mère" [Prof. van Meerbeek reacts to the "open letter" by Jeanine Lauwens and maintains his diagnostic: "Marc Dutroux poses as a victim, like his mother"]. Le Soir, 16. Retrieved from http:// archives.lesoir.be/le-pr-van-meerbeeck-reagit-a-la-lettre-ouverte-de_t-19970826-Z0E483.html

Latour, B. (1987). Science in action. Cambridge, MA: Harvard University Press.

Monfort, J.-C., \& Hourdé, I. (2005). Outils pour les entretiens d'aide et de soutien psychologique: Tome 1 [Tools for interviews of help and psychological support : Vol. 1]. Paris, France: Heures de France.

Mulkay, M. (1991). Sociology of science: A sociological pilgrimage. Milton Keyes, UK: Open University Press.

Nowotny, H. (2003). Democratizing expertise and socially robust knowledge. Science and Public Policy, 7, 369-383.

O'Donohue, W., \& Dyslin, C. (1996). Abortion, boxing and Zionism: Politics and the APA. New Ideas in Psychology, 14, 1-10.

Pupavac, V. (2004). War on the couch: The emotionology of the new international security paradigm. European Journal of Social theory, 7, 149-170.

Reicher, S. (1996). The crowd century: Reconciling theoretical failure with practical success. British Journal of Social Psychology, 35, 535-553.

Ricoeur, P. (1983). Préface [Preface]. In H. Arendt, La condition humaine [The human condition] (pp. 5-32). Paris, France: Calmann-Lévy.

Ricoeur, P. (1992). Oneself as another (K. Blamey, Trans.). Chicago, IL: University of Chicago Press. (Original work published 1990)

Rockmore, T. (1992). On Heidegger's Nazism and philosophy. Berkeley: University of California Press.

Rose, N. (1999). Governing the soul (2nd ed.). London, UK: Free Association Books.

Spears, R., \& Smith, H.J. (2001). Experiments as politics. Political Psychology, 22, 309-330.

Stengers, I. (2001). The invention of modern sciences (D.W. Smith, Trans.). Minneapolis: University of Minnesota Press. (Original work published 1993)

Stengers, I., \& Ralet, O. (1997). Drugs: Ethical choice or moral consensus? In I. Stengers, Power and invention: Situating science (P. Bains, Trans.; pp. 214-231). Minneapolis: University of Minnesota Press.

Taminiaux, J. (1997). The Thracian maid and the professional thinker: Arendt and Heidegger (M. Gendre, Trans.). Albany: SUNY Press. (Original work published 1992) 
Texto. (1997). L'interprétation du psychiatre sur le passé de Dutroux ne séduit pas sa mère [The psychiatrist's interpretation of Dutroux's past does not seduce his mother]. Le Soir, 15. Retrieved from http://archives.lesoir.be/texto-l-interpretation-du-psychiatre-sur-le-passe-dedu_t-19970820-Z0E3M0.html

Turner, J. C. (1981). Some considerations in generalizing experimental social psychology. In G. M. Stephenson \& J.M. Davis (Eds.), Progress in applied social psychology (Vol. 1, pp. 3-34). London, UK: Wiley.

Villa, D. (1996). Arendt and Heidegger: The fate of the political. Princeton, NJ: Princeton University Press.

\section{Author biography}

Denis Sindic is a Research fellow at the Institute of Social Sciences of the University of Lisbon. His main research interests are nationalism and national identities. His most recent publication (Journal of Community and Applied Social Psychology, 2011) focuses on the relationship between psychological citizenship and national identity. Address: Instituto de Ciências Sociais da Universidade de Lisboa, Av. Prof. Aníbal Bettencourt, no.9, 1600-189 Lisboa, Portugal. Email: denissindic@yahoo.co.uk 